AIDS TO SURGICAL ANATOMY (Students Aid Series)

By J. S. Baxter. 2nd Edition. Baillière, Tindall \& Cox, London, 1942. Price 4 s. $6 \mathrm{~d}$.

The second edition of this book has been revised ćarefully and a part of it re-written. A certain amount of new material has been introduced, especially in the section which deals with the Head and Neck. The book is not intended to teach the student the details of Surgical Anatomy but will be useful for a quick revision of his knowledge, especially immediately before the qualifying examination. There are twenty-six illustrations, some of which require improving, especially the diagram illustrating the lymphatic drainage of the stomach. In view of the importance of the lymphatic drainage of the breast to the surgeon dealing with malignant disease of this organ, the anatomical arrangement of the lymph nodes should be described in greater detail.

In the section dealing with amputations of the lower extremity, in view of modern surgical teaching, we feel that descriptions of such amputations as Lisfranc's and Chopart's could be omitted. Special attention should be called to the importance of dividing the posterior tibial artery as low as possible in Syme's amputation so as to ensure an adequate blood supply to the flap. The book is a valuable addition to the popular Aids ories.

\section{THE TREATMENT OF SHOCK}

By R. W. Raven, F.R.C.S. Oxford University Press. London: Humphrey Milford. r942. Price 5s.

We know little about shock, and a vast literature has grown up round the condition. In addition there is a committee duly considering the matter in London. Memoranda have been issued by the Ministry of Health to members of the profession in its employ. Summaries of these form the basis of Chapters 7 and 8 on administration of oxygen and blood transfusion respectively.

The hospitals of England have drawn off gallons of blood in anticipation of casualties which fortunately have rarely materialised. Much of the blood in the early days of the war went stale, and was used as manure on gardens or thrown away. Now the serum is decanted and the red cells discarded. One wonders whether all this was really necessary, and whether some less extravagant system could not have been evolved, i.e. the main body of donors to be on call, during certain periods, and bled as and when required. This would have obviated much promiscuous bleeding.

This book, which in itself adds nothing to our knowledge of shock, presents the known data in a readable manner in the form of an essay. It is of great importance that this knowledge should be widely diffused for many battle and air-raid casualties die from shock. It must not be overlooked that they often die before medical aid is available. If this thesis succeeds in spreading knowledge it will have served a most useful purpose.

\section{SURGERY OF MODERN WARFARE Vol. II}

Edited by Hamilton Bailey. 2nd Edition. E. \& S. Livingstone, Edinburgh. 1942. Price 40 s.

The publication of this book in two volumes is a distinct advantage; this second volume contains sections IX-XX. We welcome the chapter contributed by Professor H. J. Seddon on Injuries of the Peripheral Nerves based on his extensive experience at the Centre for these injuries at Oxford. The importance of this subject and the frequency with which these injuries occur during war time call for an authentic statement of the present position of surgical treatment. Seddon has given an excellent up-to-date account of the subject. He calls attention to the necessity of team work between surgeon and neurologist and the importance of adequate facilities for physiotherapy and follow-up of cases. The problem of Burns is dealt with in a very helpful manner by Surgeon Rear Admiral Wakeley and his contribution should be studied by all who have the management of these cases. Surgeon Rear Admiral Sir William Wheeler makes an excellent contribution on Amputations and calls for co-operation between the surgeon and artificial limb-maker. He advocates immediate encasement of the stump in plaster of Paris but early removal, thereby hurrying through the stage of shrinkage to the final state of muscular development and free joint movement. A plea is made for the performance of Syme's amputation in properly selected cases. He states that in many of the cases which failed during the last war. the operation was either contraindicated or performed under adverse conditions. The standard of production of this book is high and both editor and publishers are to be congratulated on a meritorious work.

\section{A TEXT BOOK OF MIDWIFERY FOR STUDENTS AND PRACTITIONERS}

By R. W. Johnstone, C.B.E., M.A., M.D., F.R.C.S.E., M.R.C.P.E., F.R.C.O.G., F.R.S.E. IIth Edition. A. \& C. Black, London, I942. Price 25s.

The popularity of Johnstone's Text Book of Midwifery can be judged by the fact that it has gone through eleven editions since first published in 1913. The whole work was re-organised in 1932 with the advent of the sixth edition, and any text book which runs through five editions in ten years must have much to commend it.

The outstanding new feature in this edition is an additional chapter on radiology in obstetrical diagnosis. It is illustrated with a number of excellent new radiographs. The chapter on the pathology of the new-born infant is excellent in every way, and the sections on hyperemesis gravidorum, faults in the powers, and the treatment of cephalo-pelvic disproportion have been largely re-written. The author indicates Burn's method of delivery of the after coming head in Breech delivery.

For many years this text book has been outstanding because of its lucidity and the present edition is no exception. All the important recent additions to obstetric knowledge are incorporated and the reviewer unhesitatingly recommends the work to both students and practitioners as being sound, reliable and practical. 